\title{
Nano-scale strengthening from grains, subgrains, and particles in Fe-based alloys
}

\author{
D. R. Lesuer - C. K. Syn - O. D. Sherby
}

Received: 22 February 2010/Accepted: 5 March 2010/Published online: 30 March 2010

(C) The Author(s) 2010. This article is published with open access at Springerlink.com

\begin{abstract}
Nano-scale strengthening has been studied for $\mathrm{Fe}$ and Fe-based alloys and found to be a function of grains, subgrains, and particles. In $\mathrm{Fe}-\mathrm{C} / \mathrm{O}$ alloys, these microstructural features can result from phase transformations and deformation processes. The relationships between these structural features and strength have been quantified and the limitations established. The relationships were shown to apply equally well to structures produced by deformation and quenching. The major contributors to strength were carbide and oxide particles. Particles, grains, and subgrains were shown to provide significantly higher strengthening than contributions from solid solution effects.
\end{abstract}

\section{Introduction}

Nano-scale structures in Fe-based alloys can produce exceptionally strong materials with strengths exceeding $3 \mathrm{GPa}$. These nano-scale structures include grains, subgrains, and particles and can be developed in bulk Fe and $\mathrm{Fe}-\mathrm{C} / \mathrm{O}$ alloys as a result of both severe plastic deformation (SPD) and transformation processes. Documented SPD processes, which involve deforming the material in the ferrite temperature range to strains in excess of 8 , have included ball milling, large strain deformation involving

D. R. Lesuer $(\varangle) \cdot$ C. K. Syn

Lawrence Livermore National Laboratory, Livermore,

CA 94550, USA

e-mail: lesuer1@1ln1.gov

O. D. Sherby

Stanford University, Stanford, CA 94305, USA extrusion and torsion, successive roll bonding, shear banding, and wire drawing. Transformation processes in $\mathrm{Fe}-\mathrm{C} / \mathrm{O}$ alloys that can produce nano-scale structures require heating the material into the $\gamma$-phase field followed by rapid cooling. Heating can result from adiabatic plastic deformation produced during several of the SPD processes mentioned above or can result from relatively slow heating into the $\gamma$-phase field followed by a quenching treatment. The high strengths derived from nano-scale structures produced by deformation and transformation processes is the subject of this article.

\section{Deformation structures}

\section{Materials examined}

Recent studies have shown that ball milling can produce nano-scale Fe-based materials with high strength [1]. Ball milling is an effective processing approach because SPD is readily achieved. The high strain rate during ball milling, typically $10^{4} \mathrm{~s}^{-1}$, imparts high flow stresses. The combination of large plastic deformation and high flow stress leads to the creation of fine dislocation cells, subgrains, and grains. Grain sizes in the range of 6 to $100 \mathrm{~nm}$ [2-6] have been observed in the ball-milled powders and as fine as $80-500 \mathrm{~nm}$ [7-14] in the consolidated state. Nominally pure iron powders are used as a starting material. The presence of iron oxide, as $\mathrm{Fe}_{3} \mathrm{O}_{4}$ particles, is evident after ball milling and after consolidation. Recent work has shown that the major contributors to strength are the nano-oxide particles [1]. Table 1 is summary of various investigations that have been studied to evaluate the influence of nano-structure on the strength of ball-milled iron. 


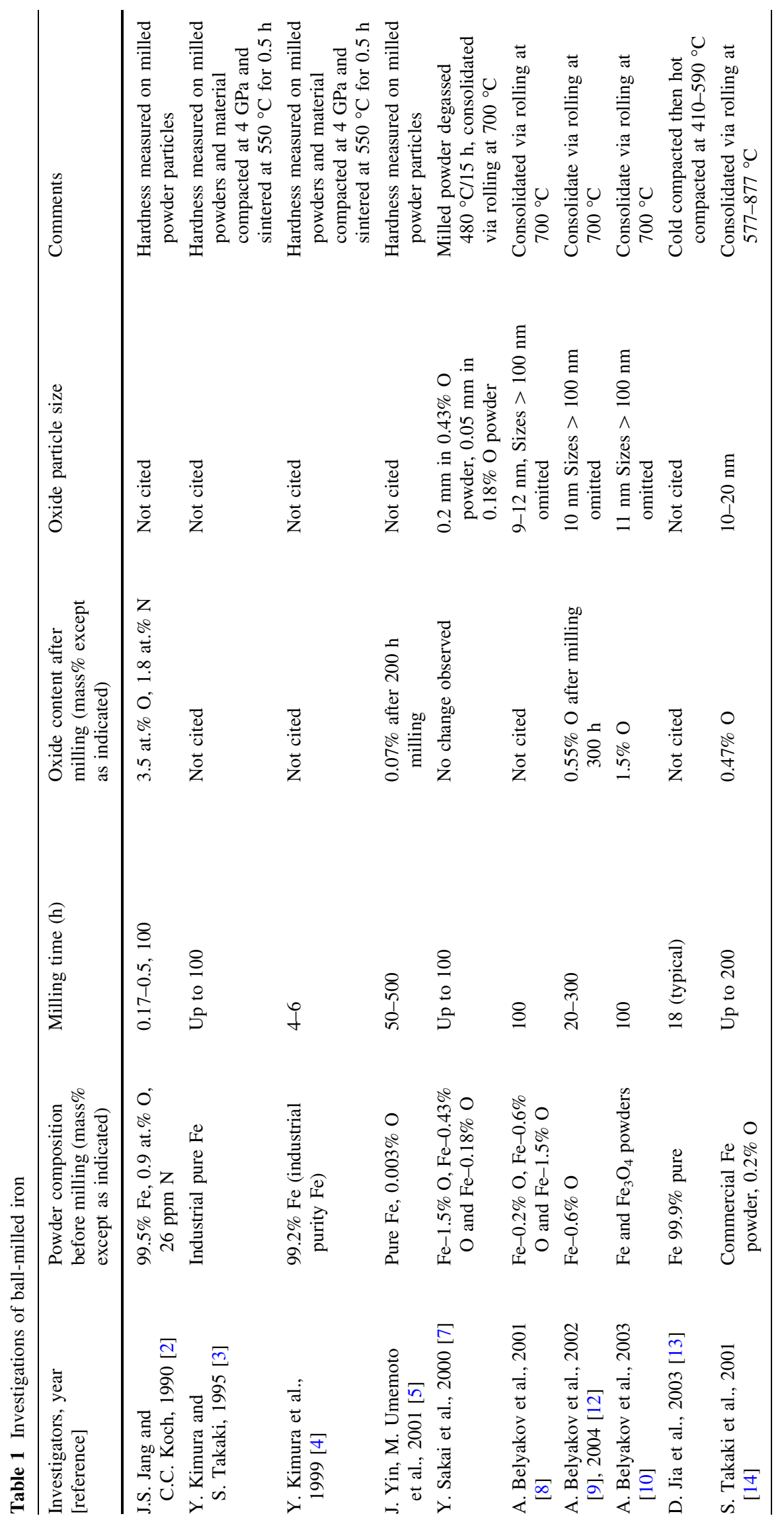


Effect of structure on strength

\section{Subgrains}

Iron powders, when ball milled for short times (less than $20 \mathrm{~h}$ ), develop nano-scale subgrains [15]. These subgrains are retained after consolidation and warm working. The influence of subgrain boundaries on strength is shown in Fig. 1 for the five studies in Table 1 with ball milling times less than $20 \mathrm{~h}[2,4,7,12,13]$. For studies in which strength is not directly reported, Vickers hardness numbers $\left(H_{\mathrm{v}}\right)$ were converted to yield strength $\left(\sigma_{\mathrm{y}}\right)$ by $\sigma_{\mathrm{y}}=H_{\mathrm{v}} / C$, where $C=3$ for $H_{\mathrm{v}}<6.5$ and $C=2.5$ for $H_{\mathrm{v}}>6.5$ [1]. The yield strength-subgrain size $(\lambda)$ data for these materials was analyzed according to the relation:

$\sigma_{\mathrm{y}}=B \lambda^{-n}+\sigma_{0}$,

where $B$ is a constant, $n$ the subgrain size exponent, and $\sigma_{0}$ the matrix strength. Rearranging Eq. 1 enables the strengthening contribution from subgrain boundaries $\left(\sigma_{\lambda}\right)$ to be established as follows:

$\sigma_{\lambda}=\sigma_{\mathrm{y}}-\sigma_{0}=B \lambda^{-n}$.

The value of $\sigma_{0}$ in this relation was assumed to be zero for these studies except for the work of Kimura et al. [4] on the $99.2 \%$ pure powders. For this material, the authors estimated that $\sigma_{0}$ was equal to $13 \mathrm{MPa}$. Plotting the resulting values of $\sigma_{\lambda}$ as a function of subgrain size on log-log axes allows an unambiguous determination of the subgrain size exponent $\mathrm{n}$. Also shown in Fig. 1 are data for three solid solution alloys of iron $(\mathrm{Fe}-3 \% \mathrm{Si}, \mathrm{Fe}-25 \% \mathrm{Cr}$, and 316 stainless steel) that were warm worked [16] and data for essentially pure iron $(\mathrm{Fe}-0.007 \mathrm{C})$ that was processed by wire drawing at room temperature [17]. The ball-milled powder and wrought data cover over two orders of magnitude in subgrain size $(30 \mathrm{~nm}$

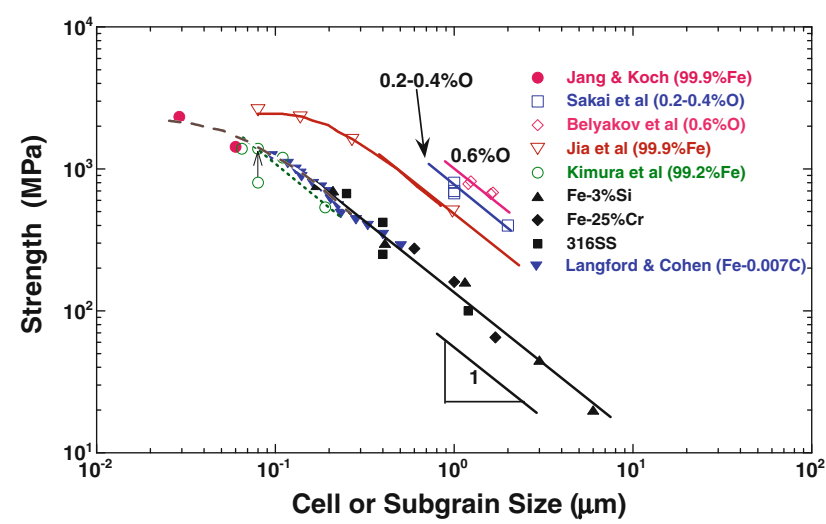

Fig. 1 Strength from subgrain boundaries versus subgrain size for ball-milled irons and several wrought iron materials. These wrought iron materials include three solid solutions of iron that were mechanically worked in torsion and a $\mathrm{Fe}-0.007 \mathrm{C}$ material that was wire drawn to $6 \mu \mathrm{m})$ and show a continuous pattern of behavior. Over most of the subgrain size range $(0.1-6 \mu \mathrm{m})$, a subgrain size exponent of -1 is observed.

Figure 1 also shows a breakdown of the $\lambda^{-1}$ relation beginning at about $0.10 \mu \mathrm{m}$. For traditional grain boundary strengthening, a breakdown in the strength-grain size relation at small grain sizes is often associated with grain boundary sliding. For subgrain boundary strengthening, the breakdown in the relation cannot be related to subgrain boundary sliding, since such boundaries only migrate and do not slide. However, as discussed by Lesuer et al. [15], shear band instabilities in the subgrain boundaries may exist at ultra-fine sizes. Also shown in Fig. 1 are data for powders that were deliberately oxidized prior to ball milling (with contents of $0.2,0.4$, and $0.6 \mathrm{wt} \%$ oxygen). The data shown in Fig. 1 support the $\lambda^{-1}$ relation expected for subgrain boundary strengthening. However, there are also significant strengthening contributions from oxide particles. This strengthening source will be discussed more in a future section.

\section{Grains}

Work by Belyakov et al. [9] on grain boundary misorientation in ball-milled $\mathrm{Fe}$ has shown that high-angle grain boundaries dominate the structure for milling times of $100 \mathrm{~h}$ and greater. The influence of these high angle grain boundaries on strength are shown in Fig. 2. Also shown in Fig. 2 are data on interstitial-free iron and steel as evaluated by Armstrong et al. [18] and Tsuji et al. [19]. The data from these two studies are plotted as the yield strength minus the matrix strength $\left(\sigma_{0}\right)$. The value of $\sigma_{0}=28 \mathrm{MPa}$ is from Cracknell and Petch [20]. This interstitial-free iron data was obtained on cast material and thus avoided

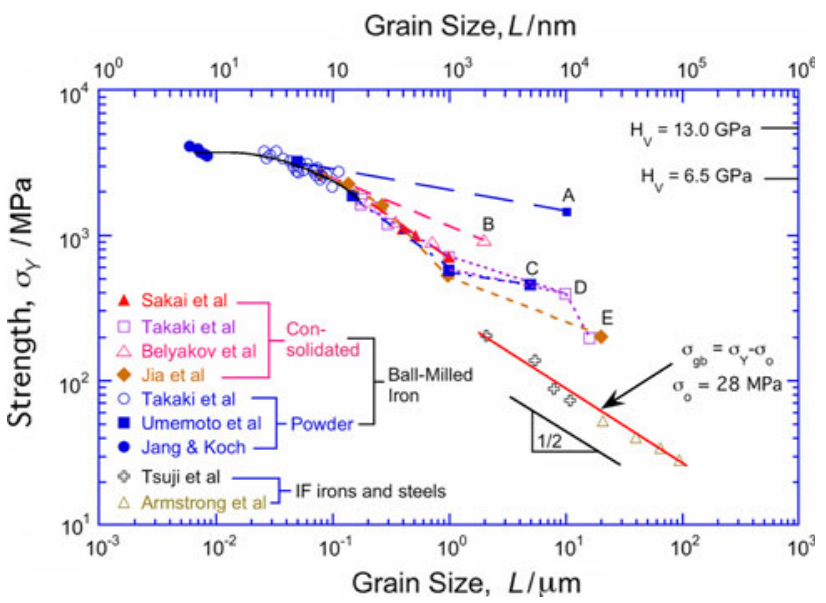

Fig. 2 Logarithm of the yield strength of ball-milled iron plotted as a function of the logarithm of the grain size. Also shown in the figure is data for wrought IF iron and steel. For these materials, the strength is plotted as the yield strength minus the matrix strength (28 MPa) 
the oxides typically found in powder-processed metals. The data clearly follows $L^{-1 / 2}$ behavior and thus follows the Hall-Petch relation.

The ball-milled data shown in Fig. 2 reveal three regions of dissimilar pattern. At ultra-fine grain sizes from 6 to about $60 \mathrm{~nm}$, the strength is seen to decrease gradually with increase in grain size. These data reveal the high hardness obtained in powders before consolidation. In the intermediate grain size range, from 0.12 to about $1 \mu \mathrm{m}$, a steep dependence of strength with grain size is observed with a grain size exponent of about 0.7 rather than 0.5 . These data are mostly from consolidated powders. The temperature of consolidation varied widely, from as low as $400{ }^{\circ} \mathrm{C}$ [13] to as high as $780{ }^{\circ} \mathrm{C}$ [14]. In the coarse grain size range, from about 1 to $20 \mu \mathrm{m}$, the data are scattered with slopes drawn for individual studies that are generally less than 0.5. These slopes are related to datum points given as A, B, C, D, and E. These samples are associated with annealing treatments at high temperatures. Each slope was drawn by joining the individual datum points to the same processed material containing a finer grain size. Data in Fig. 2 show that grain size strengthening begins to show deviation from Hall-Petch like behavior at grain sizes less than approximately $2 \mu \mathrm{m}$.

\section{Particles}

The large difference in strength between the ball-milled iron data and that for interstitial-free iron and steel, as shown in Fig. 2, is likely the result of oxide particle hardening. In studies of $\mathrm{Fe}-\mathrm{C}$ steels, the present authors have found that particles dominate the strength of the iron matrix with the conclusion that other variables contribute comparatively little to the yield strength $[1,21,22]$. These investigations led to a prediction of the strength contribution from particles by the relation:

$\sigma_{\mathrm{p}}=A \cdot\left[D_{\mathrm{s}}^{*}\right]^{-1 / 2}$,

where $\sigma_{\mathrm{p}}$ is the strength increment arising from particle strengthening and $D_{\mathrm{s}}^{*}$ is the surface to surface inter-particle spacing. The relation has been found to be equally valid for both oxide particle as well as carbide particle strengthening. The constant $A$ was determined to be $395 \mathrm{MPa} \mu \mathrm{m}^{1 / 2}$ [1]. The exponent for particle strengthening is the same as that for grain size strengthening and has been considered to have a dislocation pile-up origin [23]. Equation 4 describes the contribution of grain size and particles to the yield strength:

$\sigma_{\mathrm{y}}=k_{\mathrm{y}} \cdot L^{-1 / 2}+A \cdot\left[D_{\mathrm{s}}^{*}\right]^{-1 / 2}$.

The correlation between particle strengthening and inter-particle spacing is shown in Fig. 3 for ball-milled iron-oxygen alloys. The experimental data show excellent

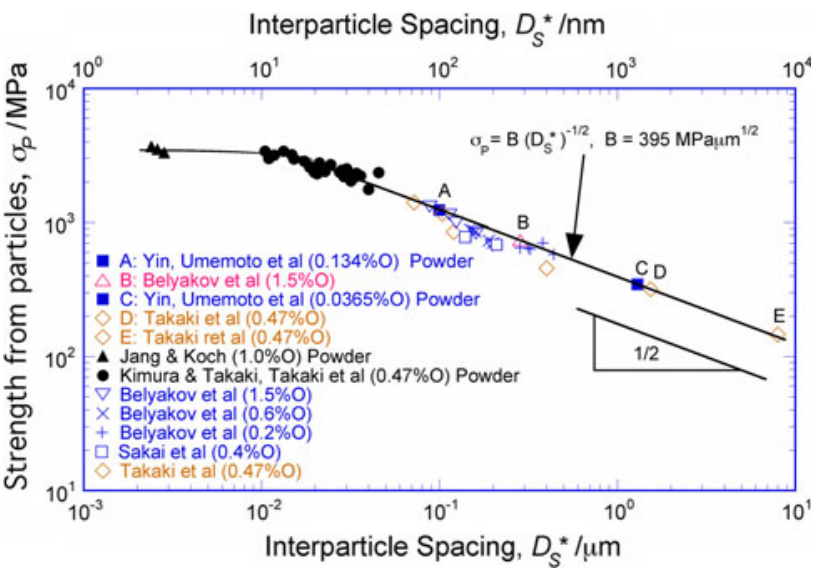

Fig. 3 Strength of ball-milled iron-oxygen alloys from particles, $\sigma_{\mathrm{p}}$, as a function of inter-particle spacing, $D_{\mathrm{s}}^{*}$

agreement with Eq. 3. The particle strengthening effect appears to diminish below about $0.02 \mu \mathrm{m}$.

\section{Transformation structures in $\mathrm{Fe}-\mathrm{C}$ steels}

Structure and strength of martensite

Martensitic transformations in $\mathrm{Fe}-\mathrm{C}$ steels are known to produce nano-scale structures and very high strengths. However, until recently, quantitative models of strength have been lacking and important experimental findings relative to structure and strength have not been explained. Key to establishing the basis for strength of martensite is understanding the role of solid solution additions. The high strength of martensite has often been attributed to solid solution hardening from interstitial carbon. In fact, martensite has been defined as a supersaturated solid solution of carbon in iron that is considered the basis of its high strength [24]. However, the work of Speich and coworkers $[25,26]$ refutes this concept. These investigators quenched a $0.03 \mathrm{wt} \% \mathrm{C}$ steel from an elevated temperature in the ferrite region $\left(725^{\circ} \mathrm{C}\right)$ to room temperature. The steel did not undergo transformation but contained the maximum amount of carbon in solution of $0.02 \mathrm{wt} \% \mathrm{C}$. The hardness of the quenched steel was measured as DPH $=110$ representing a tensile strength of $340 \mathrm{MPa}$. This strength is a factor of 2.65 lower than martensite of comparable composition, indicating that solid solution strengthening contributes very little to the strength. Furthermore the quenched steel is thermally unstable. Low temperature aging, at $60{ }^{\circ} \mathrm{C}$, leads to interstitial carbon diffusion and formation of carbides increasing the strength to DPH $=200$. The precipitation process is controlled by carbon diffusion in ferrite with the activation energy equal to $82 \mathrm{~kJ}$ per mole.

These results suggest that particles are a prominent structural feature in martensite and have an important role 
in determining strength. Recently a new model has been developed for the transformation and resulting strength in quenched $\mathrm{Fe}-\mathrm{C}$ steels $[27,28]$. The model predicts the formation of clusters, which are nano-scale embryonic particles. The model accounts for the distinct change in structure and properties of martensite at $0.6 \mathrm{wt} \% \mathrm{C}$, designated the $H^{*}$ point. Below $0.6 \mathrm{wt} \% \mathrm{C}$, martensite forms by an FCC $\rightarrow \mathrm{HCP} \rightarrow$ BCC transformation sequence. The resulting structure, which is called primary martensite, has a lath morphology and consists of two entities: (1) carbonfree, univalent BCC-iron and (2) nano-sized, carbon-rich clusters with BCC-Fe. The clusters are predicted to have a size of $6.3 \AA$. Above $0.6 \mathrm{wt} \% \mathrm{C}$, both primary and secondary martensite are produced. Secondary martensite has the much studied BCT structure with a plate morphology.

\section{Role of particles}

Figure 4 illustrates the influence of $\mathrm{C}$ on the hardness of quenched $\mathrm{Fe}-\mathrm{C}$ steels. The data are taken from a number of investigators [29-34]. Dramatic differences in the hardness-C relation are observed below and above the $H^{*}$ point. The hardness increases monotonically with increase in $\mathrm{C}$ content from near 0 to $0.6 \mathrm{wt} \% \mathrm{C}$. In this region, the increase in hardness is directly related to the increase in number of $\mathrm{C}$-rich phase particles with increase in $\mathrm{C}$ content and to the accompanying fine subgrain size. This structure is primary martensite. Upper and lower bounds are shown in the figure as solid and dashed lines, respectively. The range in strength below the $H^{*}$ point at a given $\mathrm{C}$

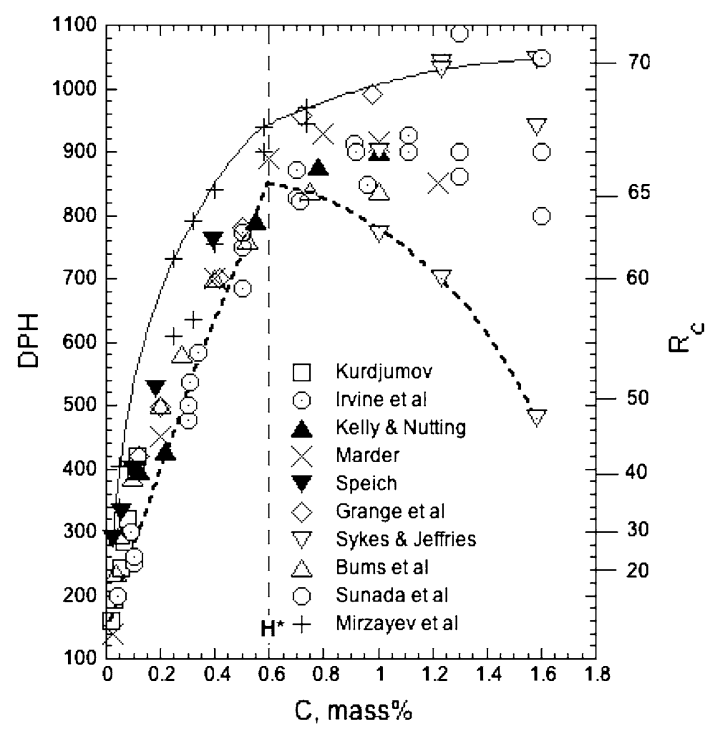

Fig. 4 Influence of $\mathrm{C}$ on the hardness of quenched $\mathrm{Fe}-\mathrm{C}$ steels. The hardness-C relation below the $H^{*}$ point is related principally to the influence of C-rich phases and subgrains. Above the $H^{*}$ point, the $\mathrm{C}$-rich phases and subgrains are still found; however, the wide scatter is attributed to the influence of retained austenite and BCT martensite concentration, which is influenced by different quenching conditions, has several possible origins. These are: (1) the size and spacing of the C-rich particles, (2) the composition of the particles, and (3) the grain/subgrain size contribution. The hardness-C relation above the $H^{*}$ point, shown in Fig. 4, reveals an entirely different pattern. A wide range of hardness is observed. This variation is caused principally by the presence of two phases that are not very effective for strengthening, namely, the two solid solution phases, BCT phase and retained FCC austenite. The continuous pattern of the maximum hardness for all $\mathrm{C}$ contents, both above and below the $H^{*}$ point, can be attributed to particle and grain/subgrain strengthening $[1,15,21]$. Above the $H^{*}$ point, strengths approaching 4.2 GPa have been produced. At these high strengths, retained austenite and BCT martensite are no longer found in the structure.

The experimental data and analysis presented above is compelling evidence for the defining role of particles in the strength of $\mathrm{Fe}-\mathrm{C}$ martensites. Further insight into the influence of particles on strength is possible by calculating the interparticle spacing responsible for the strength observed in lath martensite as presented in Fig. 4. The interparticle spacing was calculated from the known volume fraction of particles and the particle size [1]. These data are shown in Fig. 5 where the strength, in MPa, is plotted as a function of the interparticle spacing, $D_{\mathrm{s}}^{*}$ in units of $\mu \mathrm{m}$ (bottom scale) and $\mathrm{nm}$ (upper scale). Also shown in the figure are data derived from studies involving SPD as well as transformations from rapid cooling. The points from Fig. 4 are at 0.6, $0.4,0.2,0.1$, and $0.026 \mathrm{wt} \% \mathrm{C}$. The correlation allows a comparison of the interparticle spacing that is predicted for lath martensite. For the case of the $0.6 \mathrm{wt} \% \mathrm{C}$ steel, the interparticle spacing, $D_{\mathrm{s}}^{*}$, is $10 \mathrm{~nm}$ compared with the model-created sub-nm size particles. This supports the concept that the strength of martensite is principally controlled by the nano-size mechanistic model based on particles rather than on micron or nano-micron grain size.

\section{Concluding remarks}

The influence of nano-scale structure on the strength of $\mathrm{Fe}$ and $\mathrm{Fe}-\mathrm{C} / \mathrm{O}$ alloys has been studied for materials produced by both plastic deformation and phase transformation processes. These widely different processing approaches produced a consistent pattern of behavior in which strength was shown to result from subgrains, grains, and particles. The scale and resulting influence of these microstructural features is dependent on composition and processing history. Subgrain strengthening was found to vary as $\lambda^{-1}$, where $\lambda$ is the subgrain size. Grain and particle strengthening were found to vary as $L^{-1 / 2}$ and $\left[D_{\mathrm{s}}^{*}\right]^{-1 / 2}$, respectively, where $L$ is the grain size and $D_{\mathrm{s}}^{*}$ is the interparticle spacing. The 
Fig. 5 Strength of $\mathrm{Fe}-\mathrm{C}$ steels as a function of the interparticle spacing for materials subjected to different processing histories. These histories included thermal mechanical processing, shear band development during highrate deformation and quenching. The strength of lath martensite as a function of the interparticle spacing is shown as the triangle points

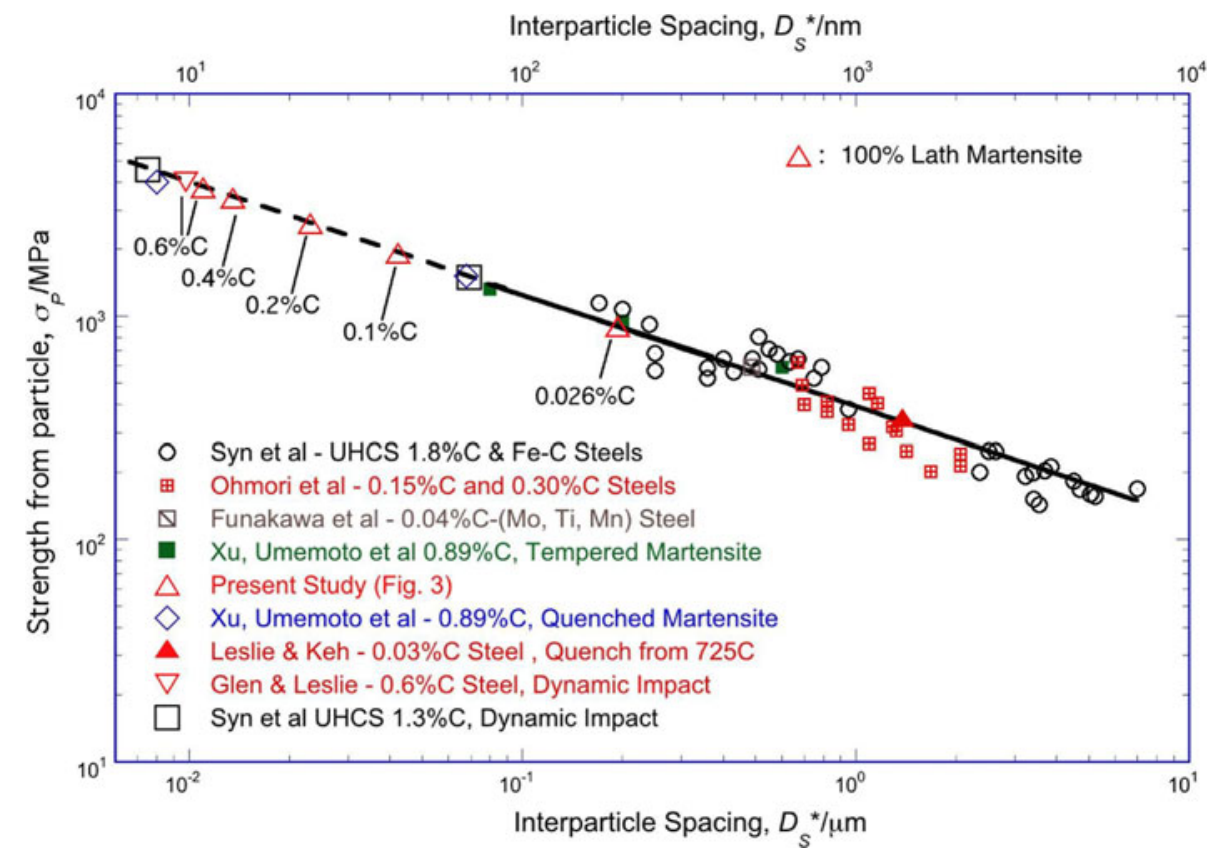

subgrain strengthening relation and the grain size strengthening relation broke down at $150 \mathrm{~nm}$ and $2 \mu \mathrm{m}$, respectively. The major contributors to strength are the nano-scale oxide and carbide particles. Analysis of data on quenched $\mathrm{Fe}-\mathrm{C}$ steels also shows that solid solution additions provide very little strengthening. The origin of nanoscale clusters, which are the basis for the dominant influence of particle hardening, is explained by a new model for the transformation and structure of quenched $\mathrm{Fe}-\mathrm{C}$ steels.

Acknowledgements This was performed under the auspices of the U.S. Department of Energy by Lawrence livermore National Laboratory under contract DE-AC52-07NA27344.

Open Access This article is distributed under the terms of the Creative Commons Attribution Noncommercial License which permits any noncommercial use, distribution, and reproduction in any medium, provided the original author(s) and source are credited.

\section{References}

1. Lesuer DR, Syn CK, Sherby OD (2006) Mater Trans 1508:47

2. Jang JCS, Koch CC (1990) Scr Metall Mater 1599:24

3. Kimura Y, Takaki S (1995) Mater Trans JIM 289:36

4. Kimura Y, Hidaka H, Takaki S (1999) Mater Trans JIM 1149:40

5. Yin J, Umemoto M, Liu ZG, Tsuchiya K (2001) ISIJ Int 1389:41

6. Umemoto M (2003) Mater Trans JIM 1900:44

7. Sakai Y, Otaguchi M, Kimura Y, Tsuzaki K (2000) In: Mishra RS et al. (eds) Ultrafine grained materials. TMS, Warrendale, PA, p 361

8. Belyakov A, Sakai Y, Hara T, Kimura Y, Tsuzaki K (2001) Metall Mater Trans 1769:32A

9. Belyakov A, Sakai Y, Hara T, Kimura Y, Tsuzaki K (2002) Metall Mater Trans 3241:33A

10. Belyakov A, Sakai Y, Hara T, Kimura Y, Tsuzaki K (2003) Metall Mater Trans 131:34A
11. Tsuzaki K (2003) Mater Sci Forum 2771:426-432

12. Belyakov A, Sakai Y, Hara T, Kimura Y, Tsuzaki K (2004) Mater Trans JIM 2252:45

13. Jia D, Ramesh KT, Ma E (2003) Acta Mater 3495:51

14. Takaki S, Kawasaki K, Kimura Y (2001) J Mater Process Technol 359:117

15. Lesuer DR, Syn CK, Sherby OD (2007) Mater Sci Eng A 54:463

16. Young CM, Sherby OD (1973) J Iron Steel Inst 640:211

17. Langford G, Cohen M (1969) Trans ASM 623:62

18. Armstrong R, Codd L, Douthwaite RM, Petch NJ (1962) Philos Mag 45:7

19. Tsuji N, Okuno S, Koizumi Y, Minamin Y (2004) Mater Trans JIM 2272:45

20. Cracknell A, Petch NJ (1955) Acta Metall 186:3

21. Syn CK, Lesuer DR, Sherby OD (1994) Metall Mater Trans 1481:25A

22. Syn CK, Lesuer DR, Sherby OD (2005) Mater Sci Technol 317:21

23. Ansell GS (1965) In: Cahn RW (ed) Physical metallurgy. North Holland Publishing Company, Amsterdam, p 887

24. ASM (1985) ASM Metals Handbook, vol 9. ASM International, Metal Park, p 11

25. Leslie WC, Keh AS (1965) Mechanical working of steel II. Gordon and Breach, New York, p 337

26. Speich GR, Leslie WC (1972) Metall Trans 1043:3

27. Sherby OD, Wadsworth J, Lesuer DR, Syn CK (2008) Mater Trans 2016:49

28. Sherby OD, Wadsworth J, Lesuer DR, Syn CK (2010) Materials science forum, vol 638-642. Trans Tech Publications, Switzerland, p 160

29. Speich GR (1969) Trans Met Soc AIME 2553:245

30. Mirzayev DA, Shteynberg VM, Ponomareva TN, Schastlivtsev VM (1980) Phys Met Metall 102:47

31. Krauss G (1978) In: Doane DV, Kirkaldy JS (eds) Hardenability concepts with application to steels. AIME, Warrendale, PA, p 229

32. Burns L, Moore TL, Archer RS (1938) Trans Am Soc Met 1:36

33. Sykes WP, Jeffries Z (1927) Trans Am Soc Steel Treat 871:12

34. Sunada H, Wadsworth J, Lin J, Sherby OD (1979) Mat Sci Eng $35: 38$ 